\title{
Uma periferia, dois centros: o município de Praia Grande no contexto da formação da macrometrópole paulista no começo do século XXI ${ }^{*}$
}

\author{
José Marcos Pinto da Cunha*^ \\ Luiz Antonio Chaves de Farias ${ }^{\star * \star}$ \\ Alberto Augusto Eichman Jakob ${ }^{\star \star \star \star}$
}

0 presente estudo tem dois objetivos principais: discutir os impactos, consequências e respostas demográficas do processo de expansão e estruturação de grandes aglomerações urbanas, com especial enfoque no caso do município de Praia Grande/SP na Região Metropolitana da Baixada Santista (RMBS); e examinar, com mais detalhes, as nuances da mobilidade populacional e, em particular, das modalidades migratórias (e suas características), como elementos importantes da peculiar inserção regional do referido município enquanto "periferia simultânea" de duas regiões metropolitanas. A partir do uso exaustivo dos dados censitários, em especial dos Censos Demográficos de 2000 e 2010, analisam-se o crescimento e a expansão territorial de Praia Grande, enfatizando, em nível intramunicipal, o papel das distintas modalidades de migração (intrametropolitana e inter-regional). Além disso, procura-se associá-las a diferentes motivações a partir de um olhar detalhado para o perfil sociodemográfico dos fluxos estabelecidos. Como principais resultados do trabalho, observou-se que o papel de Praia Grande enquanto área de expansão metropolitana da RMBS se encontra lastreado pelos crescentes fluxos migratórios intrametropolitanos provenientes do polo regional, realidade esta que igualmente pode ser vista em outros contextos metropolitanos. No entanto, enquanto peculiaridade de seu processo de ocupação e inserção regional, parte majoritária dessa migração é originária de fora da RMBS, mais precisamente do município de São Paulo, centro de outra importante área de metropolitana, fato que contribui para caracterizar Praia Grande como uma "periferia com dois centros".

Palavras-chave: Metropolização. Expansão urbana. Mobilidade populacional. Mobilidade residencial. Dinâmica socioespacial. Periferia. Migração intrametropolitana. Migração interna.

\footnotetext{
* Esse texto é fruto de reflexões realizadas no âmbito de um projeto maior que contou com o apoio da Fapesp, por meio do Centro de Estudos da Metrópole (CEM) e do CNPq. Os autores fazem um reconhecimento especial a Ana Paula Rocha dos Santos que, com seu trabalho de mestrado, inspirou o presente artigo. Para detalhes ver Santos (2008).

** Universidade Estadual de Campinas (Unicamp), Núcleo de Estudos de População “Elza Berquó” (Nepo), Campinas-SP, Brasil (zemarcos@nepo.unicamp.br; https://orcid.org/0000-0001-7097-364X).

*** Universidade Estadual de Campinas (Unicamp), Campinas-SP, Brasil (fariasax@uol.com.br; https://orcid.org/00000003-0399-7830).

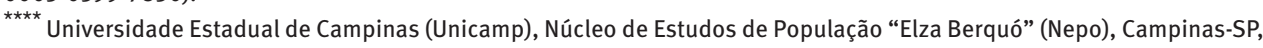
Brasil (alberto@nepo.unicamp.br; https://orcid.org/0000-0001-6905-0944).
} 


\section{Introdução}

Os movimentos populacionais podem ser vistos como uma das mais importantes respostas demográficas ao intenso processo de crescimento e expansão urbana observado nos últimos anos, especialmente em grandes aglomerações urbanas. Não há como negar que existe um grande potencial endógeno de crescimento e redistribuição espacial da população em nossas grandes metrópoles, não apenas devido à concentração demográfica nos municípios centrais, mas principalmente pelas tendências e restrições de acesso à terra, em particular por parte da população de baixa renda.

As mudanças que a mobilidade espacial da população vem experimentando durante as últimas décadas, seja na escala regional, seja na intraurbana (SOBRINO, 2007; SILVA, 2013), sugerem que a sociedade está se moldando a novos padrões de estruturação urbana que, por sua vez, também suscitam reflexões a respeito de distintas formas de relação entre os diferentes subespaços. Nesse sentido, conceitos tradicionais, como centro/periferia e espaço intraurbano e regional, devem ser também revisitados (ou, no mínimo, reinterpretados) a partir destas novas formas que, se não eliminam as tradicionais, passam a ganhar importância para a compreensão do processo mais amplo de expansão e redistribuição espacial da população.

Nesse contexto, o estudo específico do município de Praia Grande reveste-se de particular importância. Isso porque permite observar, simultaneamente, as tendências de crescimento e expansão de grandes aglomerados urbanos, características da forma tradicional de crescimento periférico, além de claras indicações de outro tipo de ocupação, condicionada não apenas pelos movimentos centrífugos dos grupos sociais mais abastados, mas, principalmente, por sua posição como importante elo entre a Região Metropolitana da Baixada Santista (RMBS) e a principal área metropolitana do estado - a Região Metropolitana de São Paulo (RMSP).

Assim, partindo de uma análise que privilegia a dinâmica demográfica e especialmente a mobilidade espacial da população, este estudo tem como principal objetivo avaliar a natureza urbano-metropolitana das articulações socioespaciais estabelecidas por Praia Grande no âmbito dos processos de expansão metropolitana da RMBS e da RMSP. Da mesma forma, o presente trabalho busca avaliar seus impactos sociodemográficos sobre a ocupação do espaço intraurbano do município, com especial enfoque sobre o fenômeno da segregação socioespacial.

Para tanto, foram utilizados os dados agregados do universo e os microdados da amostra dos Censos Demográficos de 1991, 2000 e 2010, divulgados pelo Instituto Brasileiro de Geografia e Estatística (IBGE). De forma a melhor especificar a natureza dos movimentos populacionais responsáveis pelo processo de crescimento e expansão territorial da região na análise da mobilidade espacial da população, os dados censitários sobre migração foram classificados segundo as origens destes movimentos, buscando diferenciar movimentos intra e extrametropolitanos. Finalmente, como unidades espaciais de observação, foram 
considerados os municípios e setores censitários, assim como as Áreas de Ponderação (APs), ${ }^{1}$ com o intuito de melhor verificar as consequências socioespaciais intraurbanas da inserção regional de Praia Grande e da migração.

As evidências empíricas apresentadas baseiam-se numa análise descritiva de indicadores sobre a dinâmica demográfica da região, como crescimento demográfico, migração, pendularidade e seus comportamentos segundo certas características sociodemográficas e unidades espaciais consideradas. Esta alternativa metodológica mostrou-se suficientemente robusta e eficiente para organizar e sintetizar aspectos importantes que explicam a peculiar inserção regional do município de Praia Grande do ponto de vista de sua dinâmica sociodemográfica.

Considerando que a análise empírica se guia por alguns elementos teóricos importantes para seu entendimento, ligados às novas lógicas do processo de periferização das aglomerações metropolitanas da atualidade, procede-se, na próxima seção, à apresentação e discussão dos mesmos.

\section{Teorizando a questão: sobre as formas urbanas tradicionais na metrópole contemporânea}

\section{A tradicional divisão entre centro e periferia}

O título deste estudo propositalmente incorpora um termo que, desde os anos 1990, tem sido contestado e, muitas vezes, até mesmo abandonado por ser considerado ultrapassado ou mesmo inadequado para refletir as novas tendências da expansão urbana, particularmente em nossas grandes metrópoles. De fato, no debate nacional, autores como Ribeiro e Lago (1994), Bógus (1992), Rolnik, Kowarick e Somekh (1990), entre outros, alertavam para a crescente dificuldade de considerar a distinção centro-periferia ou, pensado em outros termos, de considerar a prevalência de uma situação "dual” nas aglomerações urbanas brasileiras, já que nelas ocorreria significativa heterogeneidade da ocupação, verificando-se a proximidade geográfica de ricos e pobres, incluídos e excluídos.

Em outras palavras, nota-se que a cada década do nosso desenvolvimento urbano torna-se mais difícil e complexo fazer a distinção entre centro e periferia, no processo de estruturação de nossas metrópoles. É importante salientar que sua gênese histórica remonta o curso do século XIX, segundo Fisherman (1966), estando associada ao processo de industrialização e ao surgimento de uma classe social patente: a burguesia.

De um lado, nas cidades anglo-americanas moldadas predominantemente segundo uma lógica liberal com menos interferência estatal, a burguesia se instalou em suas periferias geográficas, longe da poluição das fábricas e dos grupos sociais de menor poder

\footnotetext{
${ }^{1}$ Os setores censitários correspondem às menores unidades espaciais de divulgação dos dados do universo dos censos demográficos; já as Áreas de Ponderação (APs) referem-se a agrupamentos de setores censitários e são as menores unidades espaciais de divulgação dos dados da amostra dos Censos Demográficos de 2000 e 2010.
} 
aquisitivo, configurando os subúrbios de classe média que conhecemos atualmente, em especial nas cidades americanas. De outro lado, nas cidades europeias continentais e latino-americanas, essa periferia geográfica seria ocupada pelos grupos sociais menos abastados, reservando-se o innercity para a residência da burguesia.

Nesse último caso, de acordo com Fisherman (1966), a ação do Estado burguês foi decisiva no sentido de "limpar" as áreas centrais das cidades do proletariado por meio de grandes reformas urbanas, como a de Haussman em Paris. Isso se deu a partir da implementação de transporte público para essas zonas periféricas, assim como por meio de incentivos fiscais para a instalação de atividades econômicas nas mesmas.

De modo geral, o processo de urbanização/metropolização brasileiro seguiu esse modelo, já que "nas cidades brasileiras, o modelo tradicional - pobreza na periferia - acentuou-se no século XX. Apenas depois dos anos 70, algo semelhante ao modelo americano surge em algumas cidades, com a edificação de condomínios ricos em terrenos afastados (tipo Alphaville)" (TASCHENER; BOGUS, 2000, p. 276).

Contudo, o que se deve perguntar é se essa nova configuração socioespacial das periferias geográficas metropolitanas elimina a vantagem de continuar a se trabalhar com as categorias centro e periferia em nossas cidades e regiões metropolitanas.

Tendemos a pensar que a resposta seria negativa. Ou seja, embora se reconheçam as mudanças ocorridas nos anos 1990 em diante, o padrão centro/periferia continua a ser válido e observável, mesmo que em escalas diferenciadas. Assim, ainda que se deva reconhecer que uma releitura da categoria "centro-periferia" é imprescindível para se dar conta da complexidade das formas que o fenômeno urbano assume nos dias atuais, isso não significa que ela esteja obsoleta para a elucidação do que é observado nas grandes metrópoles, especialmente nas latino-americanas (SOBRINO, 2007).

Dupont e Pumain (2002), respaldados em uma análise comparativa entre 19 metrópoles mundiais, observam a emergência de centros secundários em suas periferias geográficas, o que poderia supor a ocorrência de um processo de polinucleação metropolitana, rompendo com a lógica "centro-periferia”. Porém, poucos desses centros realmente assumiram uma importância na estrutura metropolitana a ponto de rivalizar com o centro principal. Em verdade, as cidades satélites metropolitanas, apesar do incremento de seu grau de centralidade, ainda mantêm grande dependência dos núcleos metropolitanos, o que pode ser atestado pelos crescentes fluxos pendulares orientados a estes últimos.

Sposito (2016) corrobora tal perspectiva analítica, ao afirmar que as cidades monocêntricas e aquelas que a autora chama de multicêntricas são muitos semelhantes entre si. As duas possuem estruturas espaciais articuladas em torno de um centro, embora a última seja caracterizada pelo aparecimento de subcentros e de outras áreas comerciais e de serviços. Esta nova configuração não significa uma ruptura da lógica anterior de estruturação dos espaços urbanos, visto que as novas áreas centrais, como já apontavam Dupont e Pumain (2002), são hierarquicamente menos importantes do que o centro, pois 
geram fluxos de menor abrangência espacial e menor densidade, em termos do número de pessoas e capacidade de consumo.

Enfim, para a divisão econômica do espaço, dada pela função dos diversos segmentos do espaço intraurbano dentro da estrutura metropolitana, a manutenção do padrão centro-periferia ainda se mostra presente. De fato, as áreas centrais ainda são protagonistas em sua função de centro comercial, de serviços e negócios, enquanto suas periferias geográficas ainda são os espaços principais de residência da população.

Todavia, no que se refere à divisão social do espaço (arranjo dos grupos sociais dentro dessa estrutura urbano-metropolitana), as mudanças são mais abrangentes, já que os próprios padrões de segregação residencial auferiram alterações importantes. Isso se percebe tanto pelo surgimento dos "enclaves fortificados" da burguesia urbana em áreas contíguas àquelas tradicionalmente ocupadas pelos grupos sociais menos abastados, quanto pela efetiva criação de áreas de residências de ocupação prioritária das elites nas periferias geográficas da cidade, seguindo os moldes da suburbanização anglo-saxônica. Assim, diante dessa complexificação da divisão social do espaço metropolitano, Caldeira (2000), baseando-se na leitura dos padrões de segregação residencial na cidade de São Paulo, observa que em nossas metrópoles ocorre, realmente, uma espécie de sobreposição de diferentes padrões de segregação e estruturação urbano-metropolitana, entre eles o tradicional centro-periferia.

Com isso, poder-se-ia falar na emergência e convivência de diferentes categorias de periferias nas principais metrópoles nacionais. De um lado, tem-se a "periferia tradicional", baseada, particularmente, no binômio loteamento popular/autoconstrução, mas também possibilitada por conjuntos habitacionais populares e caracterizada pela menor concentração de bens e serviços e menor renda diferencial da terra, ${ }^{2}$ sendo, portanto, o local por excelência de localização e reprodução social da população de baixa renda (BONDUKI; ROLNIK, 1979).

Segundo os mesmos autores, é a baixa renda diferencial da terra a característica que vincula a ocupação do território urbano à estratificação social, isto é, são os componentes geográfico e sociológico que caracterizam as periferias "tradicionais". Embora a componente distância fosse uma das principais dimensões que definiam a baixa renda diferencial desses espaços, visto que se conjugava à baixa qualidade da infraestrutura de seu ambiente construído, Bonduki e Rolnik (1979) já salientavam, nos anos 1970, que tal fato não ocorria em toda a extensão das periferias geográficas da metrópole paulista.

Isso porque, igualmente, existiam na faixa exterior da área urbanizada, tão distante do centro como as "periferias tradicionais", parcelas do território com alta renda diferencial, como, por exemplo, os loteamentos de "alto padrão", voltados para grupos sociais de

\footnotetext{
2 De acordo com Harvey (1980, p. 154-155), “a renda diferencial assume seu significado em um espaço relativo que é estruturado por diferenciais em capacidade produtiva, em localizações diferentes e que é integrado, espacialmente, através das relações de custo de transporte”. Em outras palavras, segundo Bonduki e Rolnik (1979), a renda diferencial é a componente da renda fundiária que se baseia nas diferenças entre as condições físicas e localizações dos terrenos e nos diferenciais de investimentos aplicados sobre eles ou no seu entorno.
} 
maior poder aquisitivo e, portanto, apresentando todos os melhoramentos urbanos. Os autores em questão, no entanto, ponderam que tais espaços não poderiam ser chamados de periferia, já que em sua concepção não teriam a condição fundamental para serem classificados enquanto tal, que seria justamente a baixa renda diferencial da terra.

No entanto, assim como no livro organizado por Costa (2006), advogamos aqui uma visão mais ampla de periferia, para além da noção sociológica tradicional, como sendo aqueles espaços de ocupação da estrutura urbano-metropolitana que guardam relações complexas de subordinação e complementaridade com o centro. Isto é, espaços de interface entre o ambiente construído e o não construído, entre as áreas de maior densidade na ocupação e aquelas de preservação ou rurais, entre os espaços consolidados e aqueles em processo de transformação.

Nessa concepção, as Novas periferias metropolitanas (COSTA, 2006) ou "periferias elitizadas", conforme se tem chamado, distinguir-se-iam por serem ocupadas predominantemente pela população de alta e média renda. Tais áreas não se distribuem aleatoriamente no espaço e, normalmente, surgem como novas ofertas habitacionais que oferecem "amenidades" (e não apenas a segurança) e infraestrutura, fazendo com que o aumento da distância com relação às áreas mais centrais (e muito valorizadas) da região ou das cidades também valha a pena.

\section{O complexo metropolitano do Estado de São Paulo: articulando novas formas urbanas}

Se no âmbito intrametropolitano nos deparamos com o debate sobre centro e periferia, no plano regional a questão que se coloca pertinente refere-se ao que se convencionou a chamar de urbanização dispersa (REIS FILHO, 2006). Desde a década de 1990, observa-se a emergência de uma configuração mais complexa nas grandes aglomerações urbanas, que se diferencia da grande cidade constituída no tempo pretérito.

Moura (2009) destaca que estas novas configurações espaciais transcendem a tradicional dicotomia entre espaço intraurbano - correspondente à noção de cidade construída - e a de rede urbana - referente às funções e posições das cidades em um sistema urbano de abrangência regional (VILLAÇA, 1998). O que de fato ocorre é "uma conjugação entre o urbano e regional, resultando em uma configuração híbrida, complexa e multiescalar" (MOURA, 2009, p. 28).

Dentre os fatores que podem ser apontados para a emergência dessas novas formas urbanas, destaca-se, de acordo com Mattos (2004), o surgimento de uma nova economia de aglomeração associada ao processo de reestruturação produtiva vigente desde a década de 1970 (HARVEY, 1992), que, dentre muitas de suas reconfigurações, possui como um dos seus principais aspectos uma escala geográfica ampliada. Mattos (2004) reputa este último processo aos movimentos de desverticalização do processo produtivo, o que leva a uma ampliação da divisão social e territorial do trabalho. 
Como desdobramento para o processo de urbanização das mudanças apresentadas no parágrafo anterior, tem-se a formação de uma nova morfologia metropolitana, caracterizada pela dispersão da ocupação e das atividades produtivas. Nela, um grande número de cidades e povoados não conurbados localizados exteriormente, mas perto da mancha urbana principal, passa a se articular à dinâmica metropolitana e econômica irradiada desta última, constituindo com ela uma unidade regional urbana, ainda que não haja contiguidade física de suas manchas urbanas.

Deve-se ressaltar que a dinâmica em questão não ocorre de forma aleatória, tendo em vista que, de fato, nesse processo há uma forte seletividade espacial. Esta dispersão privilegiou localidades dotadas de atributos necessários para o seu desenvolvimento e expansão, isto é, com as condições gerais de produção adequadas às atividades econômicas a serem desenvolvidas. Em geral, essas áreas correspondiam aos espaços circundantes das áreas metropolitanas e que, mesmo ainda sem serem incorporados pela mancha urbana em expansão, intensificam sua relação funcional com ela.

Dessa forma, Mattos (2004, p. 179) enumerou cinco características centrais dessa urbanização dispersa, na qual se inscrevem as “metrópoles contemporâneas”, sendo elas: configuração de sistemas produtivos centrais, organizados de forma reticular, que sustentam a formação de cidades-região; redução demográfica nas áreas centrais e forte crescimento rumo às bordas e ao periurbano; policentrismo da estrutura e do funcionamento metropolitano; urbanização dos modos de vida nas áreas intersticiais periurbanas; e proliferação de equipamentos urbanos que provocam impactos na estrutura e na imagem urbana.

No Brasil, esse novo quadro econômico, urbano e regional se consubstanciou em um processo de desconcentração do setor industrial para além das deseconomias de aglomeração presentes nas grandes áreas metropolitanas, principalmente das regiões Sul e Sudeste. Ressalta-se que tal desconcentração, em verdade, foi limitada geograficamente a um polígono onde se podia usufruir do acesso à mão de obra, aos objetos técnicos e aos mercados consumidores (AZZONI, 1986; DINIZ, 1993). Por outro lado, foi observado o reforço da centralidade exercida pelas metrópoles, a partir da concentração das atividades de controle e gestão do processo produtivo (SANTOS, 1990; MATTOS, 2010).

Para o caso do Estado de São Paulo, a urbanização dispersa materializou-se no que se convencionou a chamar de "metropolização expandida" (OLIVEIRA, 2009), correspondente ao conjunto de metrópoles do Estado de São Paulo, vislumbrada já nos anos 1970, ao menos por uma autora, com a denominação de "macrometrópole paulista" (SOUZA, 1978). ${ }^{3}$ Com o avanço do processo de metropolização no território paulista ao longo das últimas décadas, a vigência e a consolidação desta unidade regional ganharam tal importância que, a partir de 2011, a Empresa Paulista de Planejamento Metropolitano (Emplasa) passou a

\footnotetext{
${ }^{3}$ Assim definida pela Emplasa mais recentemente, esta "nova configuração urbana" é composta por 173 municípios distribuídos entre as cinco regiões metropolitanas oficiais do Estado de São Paulo, além de municípios situados nas regiões de influência de Piracicaba, Jundiaí, São Roque e Bragança Paulista.
} 
reconhecê-la oficialmente como unidade de planejamento regional, no âmbito da criação do Sistema Estadual de Desenvolvimento Metropolitano (CASTRO; SANTO JUNIOR, 2017). Assim, embora não seja uma figura político-institucional como as RMs, a macrometrópole passa a fazer parte do planejamento metropolitano paulista, em um processo sem precedentes no Brasil, elaborando-se a partir daí planos e diretrizes estratégicas, próprios dessa escala de organização do território.

Segundo Lencioni (2015), a formação da macrometrópole paulista está associada ao avanço da urbanização, da interiorização do desenvolvimento econômico e da desconcentração produtiva e populacional da RMSP, processos dos quais se desdobrou a configuração de um território marcado por significativa heterogeneidade estrutural, que acumula condições e potencialidades de desenvolvimento socioeconômico diferenciadas do restante do país e concentra, igualmente, expressiva dívida social, na forma da existência de precárias condições de moradia, de ocupação de áreas de risco, de carência de infraestruturas urbanas e sociais, etc.

Ainda de acordo com Lencioni (2015), a integração funcional entre as partes, compondo uma divisão do trabalho regional, é um dos seus principais aspectos, assim como a mescla de dinâmicas socioespaciais próprias da escala da rede urbana e do espaço urbano. As contiguidades e, sobretudo, as complementaridades socioespaciais existentes entre as diferentes unidades regionais são características marcantes e conferem unidade a essa nova formação urbana.

Funções e dinâmicas socioespaciais até então restritas a cada unidade regional passam também a serem compartilhadas por elas, definindo as complementaridades socioespaciais. Assim, respaldados pelos inúmeros pressupostos técnicos do território (rodovias, sistemas de transporte de massa, etc.), fluxos populacionais cotidianos para trabalho, estudo, lazer, etc. ganham representatividade entre as diferentes RMs (MOURA, 2009).

Dessa maneira, emergem novas dinâmicas de estruturação do espaço urbano, conformando um espaço que, se ainda não é polinucleado dentro das RMs, o é regionalmente. Logo, em uma área tão extensa quanto a macrometrópole paulista, o modelo centro-periferia pode e deve ser pensando a partir de novos matizes, já que não apenas cada região em particular poderá, em boa medida, reproduzir esse padrão (município-núcleo e sua periferia), mas também municípios de outras regiões poderão relacionar-se a municípios centrais de regiões distintas justamente pelo caráter de complementaridade socioespacial possibilitado por essa nova forma urbana. Assim, é plausível que uma mesma periferia possa compartilhar centralidades de diferentes contextos metropolitanos e vice-versa. 0 presente artigo busca mostrar que esse é o caso do município de Praia Grande em relação às metrópoles santista e paulista. 


\section{Mobilidade populacional e metropolização}

A mobilidade espacial da população se mostra um importante elo da nova dinâmica seguida pela metropolização nas últimas décadas no Brasil. Grande parte das complementaridades socioespaciais estruturantes do processo de urbanização dispersa paulista é mediada por fluxos populacionais. Cabe destacar que essa nova lógica não somente é condicionada pelas mudanças observadas no fenômeno da urbanização, mas também está relacionada com as mudanças mais gerais na dinâmica demográfica nacional, em especial a mobilidade populacional.

A história recente dos movimentos populacionais brasileiros vem sendo marcada, em uma dinâmica que já se coloca como consenso entre os principais pesquisadores sobre 0 tema (CUNHA, 2015; BAENINGER, 2011; BRITO, 2000), pela perda de destaque no cenário migratório das movimentações de alcance espacial mais distante em prol das modalidades de distâncias mais curtas, em especial aquelas de cunho intrametropolitano.

Entre os diversos fatores que condicionaram essas novas tendências, destacam-se: arrefecimento do processo de concentração espacial populacional nas grandes metrópoles do Sudeste nos anos 1970 e 1980, com redução do volume das tradicionais correntes migratórias originárias no Nordeste, Minas Gerais e Paraná; avanço da transição demográfica e da fecundidade, levando à diminuição da pressão demográfica até então existente em determinadas áreas do território brasileiro (CUNHA, 2015; MARTINE, 1994); e arrefecimento do crescimento populacional.

No âmbito metropolitano em específico, é possível perceber que tanto os movimentos migratórios de origem externa quanto os de origem interna (os quais chamaremos aqui de intrametropolitanos) podem ser decisivos para o processo de expansão e crescimento demográfico e espacial regional. No entanto, no contexto atual de significativa queda da fecundidade e redução da migração interestadual, sobretudo no que se refere ao poder de atração/retenção desta migração por parte do Estado de São Paulo, não há dúvidas de que o que ocorre internamente em termos de redistribuição espacial da população em nossas áreas metropolitanas é o que terá maior impacto sobre seus processos de expansão demográfica e espacial. ${ }^{4}$

É, portanto, indiscutível que o "potencial endógeno" ${ }^{5}$ de crescimento de nossas metrópoles, representado sobretudo pela mobilidade residencial de parcela significativa da população das áreas centrais para aquelas mais periféricas, ${ }^{6}$ é o que hoje em dia, em boa medida, possibilita explicar que, mesmo com níveis muito reduzidos de crescimento

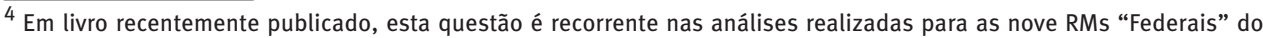
país (CUNHA, 2018).

${ }^{5}$ Entende-se como a força redistributiva interna existente nas metrópoles, fruto da combinação entre a concentração demográfica e os condicionantes do uso e ocupação do solo, seja quanto ao espaço habitado, ou à distribuição das atividades produtivas.

${ }^{6}$ Vale frisar que este padrão tradicional de movimento centrífugo de redistribuição espacial da população já começa a ter que ser repensado em função da retomada do processo de reocupação de muitas áreas centrais das grandes cidades, como bem mostra Nakano (2015) para a cidade de São Paulo.
} 
demográfico regional (e o caso da RMBS é exemplar), muitos de seus municípios continuam apresentando grande intensidade de crescimento e expansão demográfico-territorial (DUPONT, 2002).

Assim, se, por um lado, elementos estruturais, especialmente aqueles ligados às diferenças em termos de desenvolvimento socioeconômico, em geral, e do mercado de trabalho, em particular, têm condicionado a migração de mais longa distância - principalmente a interestadual (BRITO, 2009) -, por outro, no caso dos movimentos intrametropolitanos, os condicionantes parecem ser outros, como mostram vários estudos sobre o tema (DOTA, 2015; CUNHA, 2015; CAIADO, 2006; JAKOB, 2003; MATOS, 1994). Sobrino (2007) sugere até mesmo não considerar tais movimentos como migração, preferindo denominá-los como “mobilidade residencial".

Grosso modo, poder-se-ia dizer que o mercado de terras e o de trabalho seriam apontados como os principais fatores motivadores da migração no ambiente metropolitano, ou, de maneira mais ampla, nas grandes aglomerações urbanas (MATOS, 1995). Estudos mais recentes, como os de Dota (2015), Nakano (2015) e Pinho (2016), exploram tais argumentos e mostram a importância dos estudos demográficos para a cabal compreensão do processo de expansão e diferenciação socioespacial das metrópoles. Na verdade, tal realidade não foge ao contexto metropolitano em que está inserido o município de Praia Grande, conforme poderá ser visto com mais detalhamento na próxima seção desse trabalho.

\section{Praia Grande e a dinâmica de expansão da RMBS}

Praia Grande é um dos nove municípios da RMBS e teve seu crescimento populacional privilegiado também pelo processo de metropolização da Baixada Santista. Embora existam muitos pontos em comum com outras regiões metropolitanas, as especificidades da RMBS são de extrema importância para entender seu processo de ocupação e dinâmica populacional, além de sua peculiar inserção regional.

Dentre estas particularidades, podem-se citar aspectos mais gerais, como as características geomorfológicas do seu território (delimitado pela Serra do Mar e pelo Oceano Atlântico, sendo formado por ilhas, morros, planícies, mangues e vales), a existência de um importante porto na cidade de Santos, a industrialização, em especial em Cubatão, além da vocação turística.

Quanto à Praia Grande, especificamente no âmbito intrametropolitano, a melhoria de acessibilidade a partir da construção da Ponte do Mar Pequeno e a duplicação da Rodovia Padre Manoel da Nobrega, aliadas à atuação do mercado imobiliário formal e informal, disponibilizando uma oferta de moradia "mais barata”, condição não encontrada na já saturada Ilha de São Vicente, são importantes condicionantes que explicam a emergência do município enquanto principal frente de expansão metropolitana, como será visto adiante.

No que se refere à inserção regional, ressalta-se o importante papel exercido pela proximidade geográfica com a RMSP e, principalmente, a melhoria da ligação rodoviária 
entre as duas regiões, por meio da construção da Rodovia dos Imigrantes, o que contribuiu para diminuir substancialmente o tempo de deslocamento entre a baixada e o planalto. Também se destaca a atuação do mercado imobiliário voltado não apenas para o turismo e a "segunda residência" de determinados grupos sociais do planalto, mas também para oferta de residência permanente aos mesmos, com uma grande vantagem: a proximidade ao mar. De fato, tais condicionantes poderiam explicar, em grande medida, as complementaridades socioespaciais estabelecidas mais recentemente entre Praia Grande e a RMSP, bem como o papel de destaque dos fluxos migratórios originários do planalto em sua dinâmica sociodemográfica interna.

\section{Da migração em Praia Grande: características e especificidades sociodemográficas}

Com relação ao papel de Praia Grande no processo de redistribuição espacial da população da Baixada Santista, verifica-se que o município respondia, em 1970, por cerca de 3\% da população total da RMBS, passando para 13\% em 2000 e quase 16\% em 2010 (Tabela 1), incremento que reflete as altas taxas de crescimento demográfico experimentadas nas várias décadas. Em 1970/80, o valor registrado foi de 13\% a.a., mantendo nas duas décadas seguintes um expressivo crescimento de mais $5 \%$ ao ano e, mesmo com um arrefecimento significativo, nos anos 2000 cresceu quase três vezes mais do que a média regional (Tabela 2). Com uma população que chegava a mais de 260 mil habitantes, em 2010, e que, segundo estimativas da Fundação Seade, alcança pouco mais de 300 mil, em 2017, Praia Grande é, sem dúvidas, um dos municípios que ainda hoje mais crescem na RMBS.

TABELA 1

População residente e participação na população regional Municípios da RMBS - 1970-2010

\begin{tabular}{|c|c|c|c|c|c|c|c|c|c|c|}
\hline \multirow{3}{*}{ Municípios } & \multicolumn{10}{|c|}{ População residente } \\
\hline & \multicolumn{2}{|c|}{1970} & \multicolumn{2}{|c|}{1980} & \multicolumn{2}{|c|}{1991} & \multicolumn{2}{|c|}{2000} & \multicolumn{2}{|c|}{2010} \\
\hline & $\mathrm{N}$ & $\begin{array}{c}\% \\
\text { RMBS }\end{array}$ & $\mathrm{N}$ & $\begin{array}{c}\% \\
\text { RMBS }\end{array}$ & $\mathrm{N}$ & $\begin{array}{c}\% \\
\text { RMBS }\end{array}$ & $\mathrm{N}$ & $\begin{array}{c}\% \\
\text { RMBS }\end{array}$ & $\mathrm{N}$ & $\begin{array}{c}\% \\
\text { RMBS }\end{array}$ \\
\hline Bertioga & - & - & - & - & 11.307 & 0,93 & 29.771 & 2,02 & 47.645 & 2,86 \\
\hline Cubatão & 50.506 & 7,78 & 78.439 & 8,19 & 90.866 & 7,48 & 108.135 & 7,34 & 118.720 & 7,13 \\
\hline Guarujá & 93.224 & 14,36 & 150.347 & 15,70 & 208.818 & 17,19 & 264.235 & 17,93 & 290.752 & 17,47 \\
\hline Itanhaém & 14.353 & 2,21 & 27.245 & 2,84 & 45.619 & 3,75 & 71.694 & 4,86 & 87.057 & 5,23 \\
\hline Mongaguá & 5.155 & 0,79 & 9.828 & 1,03 & 18.781 & 1,55 & 34.897 & 2,37 & 46.293 & 2,78 \\
\hline Peruíbe & 6.849 & 1,06 & 18.241 & 1,90 & 32.676 & 2,69 & 51.237 & 3,48 & 59.773 & 3,59 \\
\hline Praia Grande & 19.297 & 2,97 & 65.374 & 6,82 & 122.354 & 10,07 & 192.769 & 13,08 & 262.051 & 15,75 \\
\hline Santos & 344.347 & 53,04 & 416.418 & 43,47 & 417.114 & 34,33 & 417.975 & 28,36 & 419.400 & 25,20 \\
\hline São Vicente & 115.438 & 17,78 & 191.997 & 20,04 & 267.445 & 22,01 & 303.199 & 20,57 & 332.445 & 19,98 \\
\hline Total RMBS & 649.169 & 100,00 & 957.889 & 100,00 & 1.214 .980 & 100,00 & 1.473 .912 & 100,00 & 1.664 .136 & 100,00 \\
\hline Estado SP & 17.670 .013 & & 24.953 .238 & & 31.436 .273 & & 36.974 .378 & & 41.262.199 & \\
\hline
\end{tabular}

Fonte: IBGE. Censos Demográficos 1970, 1980, 1991, 2000 e 2010. Tabulações especiais dos autores. 
TABELA 2

Taxas de crescimento populacional médio anual Municípios da RMBS - 1970-2010

\begin{tabular}{lcccc}
\hline \multicolumn{1}{c}{ Municípios } & \multicolumn{4}{c}{ Taxas de crescimento (\% a.a.) } \\
\cline { 2 - 5 } & $\mathbf{1 9 7 0 / \mathbf { 1 9 8 0 }}$ & $\mathbf{1 9 8 0 / \mathbf { 1 9 9 1 }}$ & $\mathbf{1 9 9 1 / \mathbf { 2 0 0 0 }}$ & $\mathbf{2 0 0 0 / 2 0 1 0}$ \\
\hline Bertioga & - & - & 11,36 & 4,81 \\
Cubatão & 4,50 & 1,35 & 1,95 & 0,94 \\
Guarujá & 4,90 & 3,03 & 2,65 & 0,96 \\
Itanhaém & 6,62 & 4,80 & 5,15 & 1,96 \\
Mongaguá & 6,67 & 6,06 & 7,13 & 2,87 \\
Peruíbe & 10,29 & 5,44 & 5,13 & 1,55 \\
Praia Grande & 12,98 & 5,86 & 5,12 \\
Santos & 1,92 & 0,02 & 0,02 & 0,03 \\
São Vicente & 5,22 & 3,06 & 1,40 & 0,93 \\
\hline Total RMBS & $\mathbf{3 , 9 7}$ & $\mathbf{2 , 1 8}$ & $\mathbf{1 , 2 2}$ \\
\hline Estado SP & $\mathbf{3 , 5 1}$ & $\mathbf{2 , 1 2}, \mathbf{2 1}$ & $\mathbf{1 , 1 0}$ \\
\hline
\end{tabular}

Fonte: IBGE. Censos Demográficos 1970, 1980, 1991, 2000 e 2010. Tabulações especiais dos autores.

É evidente que este elevado crescimento demográfico, em sua grande parte, poderia ser explicado pela importância do componente migratório na dinâmica municipal. Na verdade, mesmo considerando que as tendências migratórias em nível regional não parecem sugerir que a RMBS seja marcadamente uma área de grande atração populacional (Gráfico 1), não se pode perder de vista que o fenômeno migratório, particularmente aquele de origem interna, é ainda fundamental para se entender o processo de crescimento de áreas mais periféricas da região. De fato, embora a RMBS e principalmente a sua sede, Santos, tenham reduzido o volume e, sobretudo, sua taxa de migração líquida ao longo dos últimos 30 anos do século passado, pode-se perceber que o mesmo não ocorre com os municípios que compõem os vetores de expansão sul, como Praia Grande, Mongaguá, Itanhaém e até mesmo Peruíbe, para cujos incrementos populacionais a migração foi o grande fator explicativo (Gráfico 2). ${ }^{7}$ Configura-se, assim, o que se tem chamado de "potencial endógeno" de crescimento da região.

Dados apresentados por outros estudos sobre a região (JAKOB, 2003; CUNHA; JAKOB, 2005; FARIAS, 2018) indicam que, no caso de Praia Grande, 91\% do crescimento demográfico total na década de 1970 pode ser creditado à migração, sendo que os percentuais nas décadas seguintes, embora menores, ainda permaneceram significativos. Como se percebe no Gráfico 2, mesmo reduzindo o seu peso relativo, a migração ainda continua sendo a protagonista do crescimento municipal (assim como de vários outros municípios), representando, respectivamente, $74 \%$ e $67 \%$ do crescimento demográfico das décadas de 1990 e 2000.

\footnotetext{
${ }^{7} 0$ município de Santos não foi incluído nesse gráfico em função de seu valor assumir uma escala numérica que distorceria a visualização das demais (cerca de $-952 \%$ no período $2000-2010$ ). Achou-se por bem excluí-lo para facilitar a visualização do comportamento dos componentes dos demais municípios.
} 


\section{GRÁFICO 1}

Saldo migratório e taxas de migração líquida

RMBS e município de Santos - 1970-2010

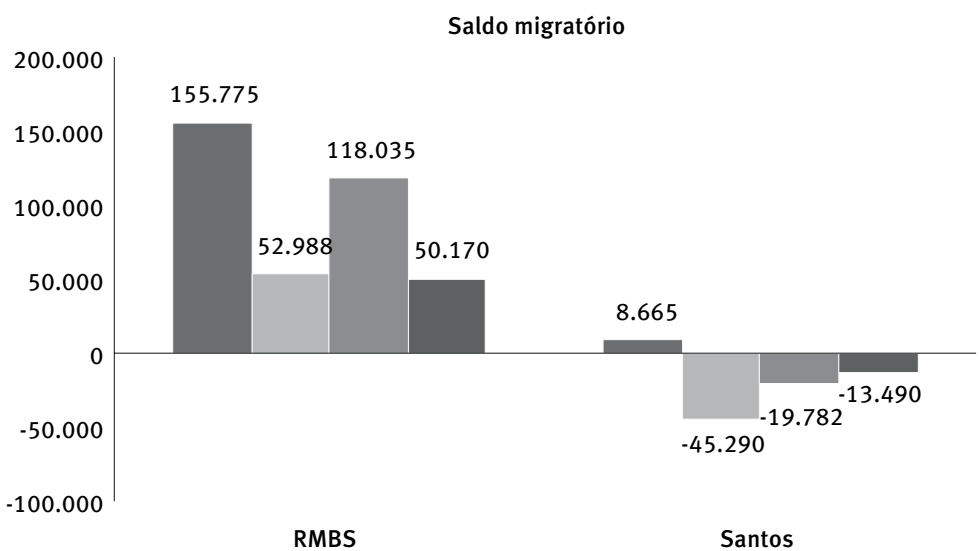

$1970 / 1980$

$1980 / 1991$

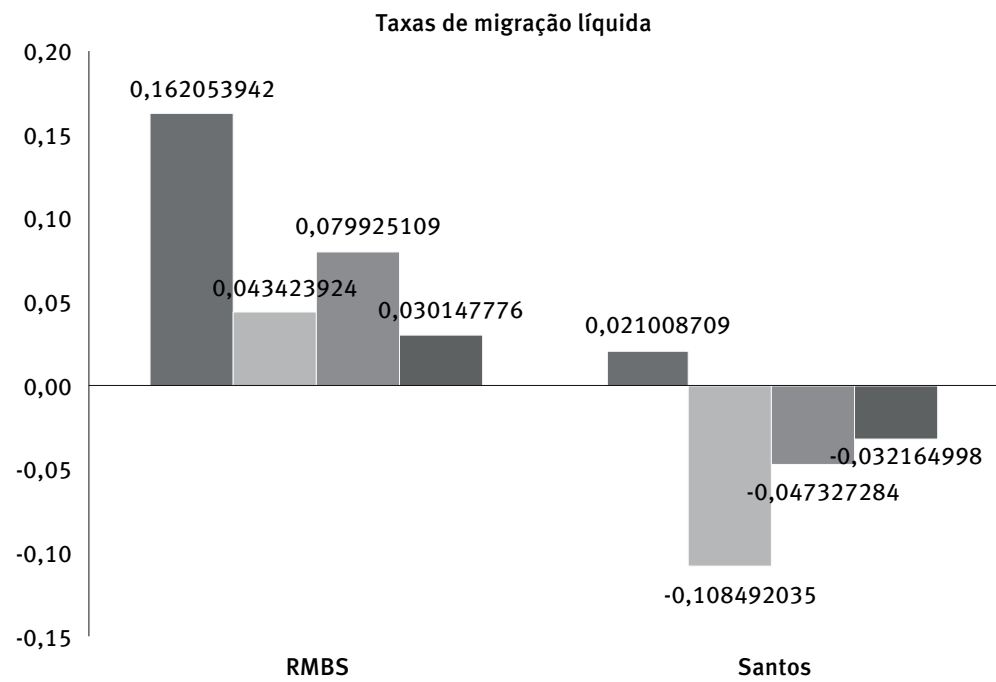

$1991 / 2000$

$2000 / 2010$

Fonte: Fundação Seade. Informações dos Municípios Paulistas (IMP), 1970 a 2010. Tabulações especiais dos autores. 


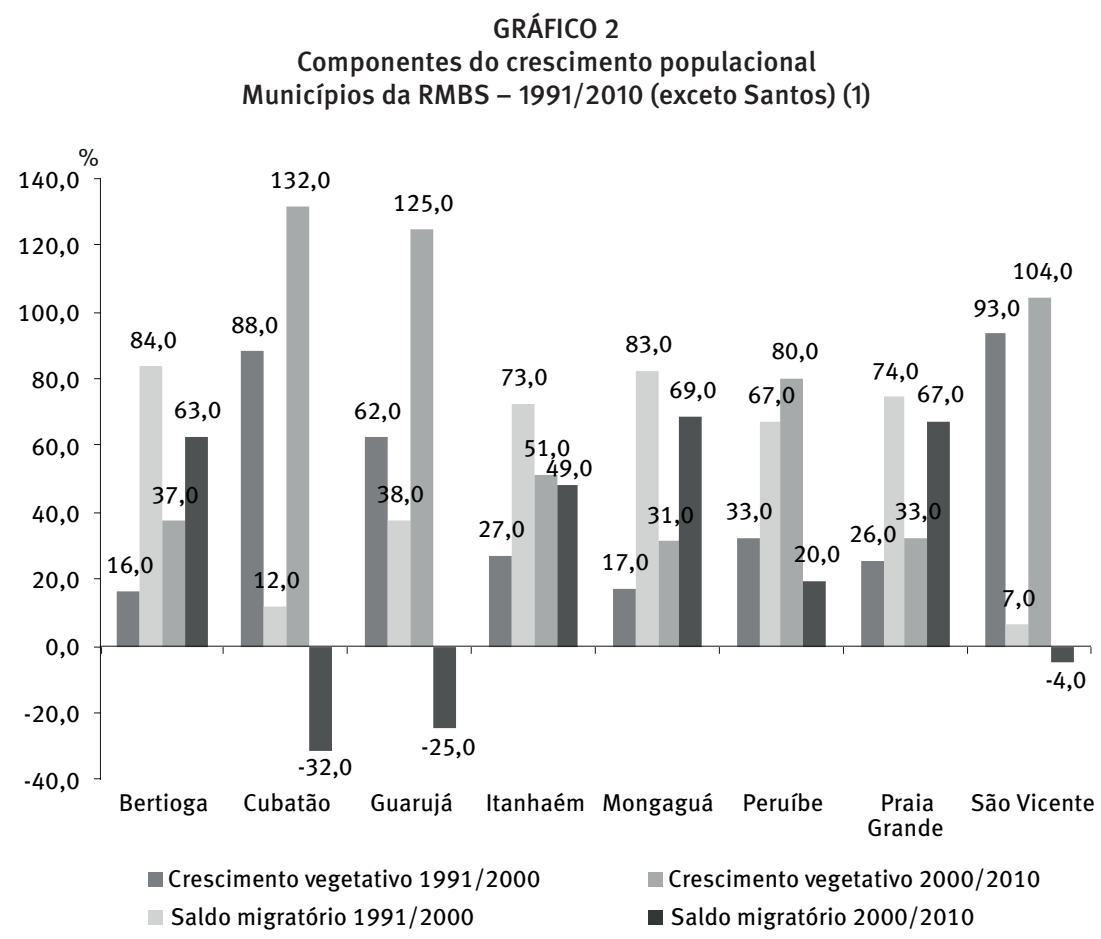

Fonte: Fundação Seade. Informações dos Municípios Paulistas (IMP), 1970 a 2010. Tabulações especiais dos autores.

(1) Os valores referentes ao peso da migração no crescimento populacional do município de Santos para 1991-2000 e 2000-2010 foram, respectivamente, de $-37114 \%$ e $-952 \%$. Ressalta-se que os valores negativos podem chamar a atenção, mas eles estão corretos e apenas mostram que a migração líquida negativa neste município teria implicado uma redução da população não fosse o efeito contrário do crescimento natural. Desse modo, optou-se por omitir os mesmos do gráfico a fim de não afetarem a sua escala de representação.

Na verdade, a mobilidade populacional possui um papel importante não só na dinâmica demográfica de Praia Grande, como também para a expansão urbana da Baixada Santista. O município, que foi privilegiado pelo processo de metropolização na condição de periferia, apresenta uma migração diversificada tanto em termos de suas modalidades, quanto com relação ao perfil dos migrantes. De fato, tal diversidade se justifica pelos distintos papéis que tais deslocamentos possuem sobre a dinâmica urbana local. ${ }^{8}$

Nesse sentido, podem ser feitas algumas constatações muito interessantes quando se observam mais detalhadamente tanto a origem quanto o perfil dos migrantes em Praia Grande. Analisando a imigração para os municípios da RMBS por modalidade entre $2000 \mathrm{e}$ 2010 (Tabela 3), verifica-se, em primeira instância, que Praia Grande foi o único município da região que registrou aumento do volume de imigrantes entre os períodos em questão, fato que caracteriza a municipalidade como a principal área de atração migratória regional.

Ademais, constata-se que a migração de mais curta distância em Praia Grande ganhou peso entre 2000 e 2010, em detrimento daquela proveniente de mais longa distância, como

\footnotetext{
${ }^{8}$ As análises de migração são baseadas no quesito que investiga a residência cinco anos antes do censo demográfico, o qual permite não apenas identificar o indivíduo que já viveu fora do município, em um período fixo de tempo, mas também a sua origem. Para mais detalhes ver Rigotti (2011).
} 
a interestadual, que, apesar de ainda manter um relativo papel de destaque, viu sua participação cair de cerca de $21 \%$ para $15 \%$, entre os dois períodos considerados. No que se refere à migração de curta distância, destaca-se que esta se subdividiu em importância entre duas origens: a intrametropolitana e a RMSP, mais especificamente o município de São Paulo.

A imigração intrametropolitana em Praia Grande nos quinquênios considerados (1995/2000 e 2005/2010) representava cerca de 30\% da migração para o município e aproximadamente $7 \%$ e $5 \%$ de sua população, respectivamente. Não é demais destacar que a origem deste fluxo provém, principalmente, do que se poderia chamar de núcleo da metrópole - Santos e São Vicente -, municípios representativos, cada um, de 38\% dos fluxos intrametropolitanos em 2010. Já a migração proveniente da RMSP respondia por cerca de $40 \%$ e $43 \%$ das migrações para Praia Grande nos anos de 2000 e 2010, respectivamente, e por quase $10 \%$ da população total do município nos dois momentos estudados.

Um dado importante a se destacar é que aproximadamente $73 \%$ deste fluxo tem origem no município de São Paulo em 2000, valor que se elevou para 77\% em 2010. Tal resultado mostra o ganho de protagonismo da mobilidade residencial proveniente da capital como importante força demográfica para a expansão urbana do município de Praia Grande.

TABELA 3

Migrantes de “data fixa”, por modalidade migratória Municípios da RMBS - 1995/2000-2005/2010

\begin{tabular}{|c|c|c|c|c|c|c|c|c|}
\hline \multirow{2}{*}{$\begin{array}{l}\text { Municípios } \\
\text { (destino) }\end{array}$} & \multirow{2}{*}{ Período } & \multicolumn{5}{|c|}{ Modalidade migratória (origem) (\%) } & \multicolumn{2}{|c|}{$\begin{array}{c}\text { Total de } \\
\text { imigrantes }\end{array}$} \\
\hline & & Interestadual & Intraestadual & Capital & $\begin{array}{l}\text { Outros } \\
\text { RMSP }\end{array}$ & Intrametropolitano & $\%$ & $\mathrm{~N}$ \\
\hline \multirow{2}{*}{ Bertioga } & $1995-2000$ & 45,40 & 9,58 & 16,56 & 17,09 & 11,36 & 100,00 & 8.995 \\
\hline & $2005-2010$ & 36,90 & 9,61 & 16,32 & 22,93 & 14,25 & 100,00 & 8.158 \\
\hline \multirow{2}{*}{ Cubatão } & $1995-2000$ & 59,46 & 10,38 & 3,69 & 1,96 & 24,51 & 100,00 & 9.494 \\
\hline & $2005-2010$ & 59,19 & 7,90 & 5,48 & 2,84 & 24,59 & 100,00 & 7.589 \\
\hline \multirow{2}{*}{ Guarujá } & $1995-2000$ & 51,48 & 11,85 & 13,53 & 4,36 & 18,78 & 100,00 & 24.627 \\
\hline & $2005-2010$ & 39,58 & 14,12 & 17,20 & 6,09 & 23,01 & 100,00 & 13.714 \\
\hline \multirow{2}{*}{ Itanhaém } & $1995-2000$ & 16,87 & 13,77 & 40,91 & 14,50 & 13,95 & 100,00 & 16.222 \\
\hline & $2005-2010$ & 11,49 & 13,83 & 42,01 & 20,17 & 12,50 & 100,00 & 15.208 \\
\hline \multirow{2}{*}{ Mongaguá } & $1995-2000$ & 13,74 & 13,25 & 43,30 & 13,12 & 16,60 & 100,00 & 11.541 \\
\hline & $2005-2010$ & 5,26 & 8,14 & 55,90 & 17,84 & 12,86 & 100,00 & 10.521 \\
\hline \multirow{2}{*}{ Peruíbe } & $1995-2000$ & 10,62 & 20,53 & 36,04 & 17,13 & 15,68 & 100,00 & 11.676 \\
\hline & $2005-2010$ & 13,24 & 17,59 & 38,09 & 18,35 & 12,73 & 100,00 & 8.424 \\
\hline \multirow{2}{*}{ Praia Grande } & $1995-2000$ & 20,81 & 9,72 & 29,04 & 10,76 & 29,66 & 100,00 & 46.409 \\
\hline & $2005-2010$ & 15,53 & 9,41 & 33,76 & 9,99 & 31,32 & 100,00 & 47.231 \\
\hline \multirow{2}{*}{ Santos } & $1995-2000$ & 36,90 & 13,85 & 17,01 & 5,49 & 26,76 & 100,00 & 31.252 \\
\hline & $2005-2010$ & 31,67 & 16,62 & 22,43 & 4,34 & 24,94 & 100,00 & 27.056 \\
\hline \multirow{2}{*}{ São Vicente } & $1995-2000$ & 26,01 & 7,58 & 11,07 & 3,45 & 51,89 & 100,00 & 34.470 \\
\hline & $2005-2010$ & 24,23 & 9,97 & 11,60 & 5,81 & 48,39 & 100,00 & 29.555 \\
\hline \multirow{2}{*}{ RMBS } & $1995-2000$ & 29,85 & 11,50 & 22,41 & 8,51 & 27,74 & \multirow{2}{*}{\multicolumn{2}{|c|}{$\begin{array}{ll}100,00 & 194.686 \\
100,00 & 167.454\end{array}$}} \\
\hline & 2005-2010 & 23,53 & 11,73 & 26,89 & 10,16 & 27,68 & & \\
\hline
\end{tabular}

Fonte: IBGE. Censos Demográficos 2000 e 2010. Tabulações especiais dos autores. 
Deve-se ressaltar que o deslocamento desde a RMSP difere completamente daquele de caráter intrametropolitano em termos de tempo e custo, o que certamente se reflete nos volumes e características da mobilidade pendular que, por sua vez, em boa medida está relacionada ao processo migratório, sendo em muitos casos uma contrapartida imediata. Portanto, embora exista uma semelhança em termos da distância, esses fluxos se diferenciam em vários outros aspectos.

Da mesma forma, tais diferenças são esperadas em relação às demais modalidades migratórias (intraestadual e interestadual), assim como na comparação entre os residentes por condição migratória ("migrante" ou “não migrante")). Isso porque os condicionantes dos movimentos tendem a mudar segundo a sua modalidade, implicando respostas sociodemográficas distintas e, portanto, seletividades diferenciadas.

De fato, a análise da migração segundo o nível de instrução dos responsáveis pelos domicílios permite que se constate a validade destes pressupostos. De forma geral, o perfil da migração intrametropolitana mostra-se bastante diferenciado quando comparado ao dos demais residentes em Praia Grande e dos imigrantes provenientes da RMSP.

Nesse sentido, o índice de seletividade ${ }^{10}$ por nível de instrução do responsável pelo domicílio (Tabela 4) ajuda a melhor visualizar as diferenças entre esses imigrantes e outras modalidades, bem como com relação aos "não migrantes".

Na comparação entre os "não migrantes" e as demais modalidades, percebe-se existir clara distinção, uma vez que os imigrantes intrametropolitanos tendem a apresentar melhores condições quanto à escolaridade, tendo em vista que este fluxo detém maior proporção de pessoas com maior nível de escolaridade.

No entanto, considerando a seletividade em comparação com os outros tipos de migrantes, percebe-se que, para os intrametropolitanos, existe uma baixa predominância no grupo "sem instrução ou fundamental incompleto" (muito menor principalmente se comparado aos outros migrantes de longa distância - intra e interestaduais). Como seria de se esperar, tendência inversa é verificada para os níveis mais altos de instrução.

Quando a comparação é realizada com os responsáveis imigrantes oriundos da RMSP, verifica-se que a seletividade tende a ser menor do que aquela observada para as demais modalidades, já que os valores ficaram mais próximos de 0 . No entanto, fica evidente um considerável aumento da seletividade em 1995-2000, que se revela pela menor

\footnotetext{
9 Nesse estudo considera-se "não migrante" todo indivíduo natural do município ou aquele que lá reside há mais de dez anos. Trata-se, portanto, de supor que as características dos nativos e moradores antigos (portanto, já inseridos e adaptados) seriam as que representariam o perfil básico do município.

${ }^{10} \mathrm{O}$ índice de seletividade é calculado pela fórmula:

$I S=\frac{\% M_{i}-\% N_{i}}{\% M_{i}+\% N_{i}} * K$

Onde: $\mathrm{Mi}$ e $\mathrm{Ni}$ são a população migrante intrametropolitana e a não migrante (ou outros migrantes), respectivamente, na categoria $i$; e $K$ é uma constante, a qual para o presente trabalho adotou-se 100. Sendo assim, o índice pode variar de -100 a 100 , sendo que os valores negativos indicam uma sub-representação relativa dos migrantes intrametropolitanos ao grupo de comparação e os valores positivos apontam predomínio desses migrantes na categoria em questão.
} 
representatividade dos responsáveis imigrantes intrametropolitanos com nível superior, em relação àqueles em mesma condição que vieram da RMSP.

TABELA 4

Índices de seletividade dos migrantes de "data fixa" intrametropolitanos com relação aos demais residentes, por nível de instrução

Município de Praia Grande - 1986/1991-2005/2010

\begin{tabular}{lccccc}
\hline \multirow{2}{*}{$\begin{array}{c}\text { Condição e } \\
\text { modalidade } \\
\text { migratória }\end{array}$} & Período & \multicolumn{4}{c}{ Nível de instrução } \\
\cline { 3 - 6 } & $\begin{array}{c}\text { Sem instrução } \\
\text { e fundamental } \\
\text { incompleto }\end{array}$ & $\begin{array}{c}\text { Fundamental } \\
\text { completo e médio } \\
\text { incompleto }\end{array}$ & $\begin{array}{c}\text { Médio completo } \\
\text { e superior } \\
\text { incompleto }\end{array}$ & $\begin{array}{c}\text { Superior } \\
\text { completo }\end{array}$ \\
\hline Não migrante & $1986-1991$ & $-6,8$ & 10,6 & 23,6 & 41,2 \\
Outros migrantes & $-9,2$ & 18,3 & 43,2 & 23,8 \\
RMSP & 1,1 & $-5,7$ & 1,9 & $-1,4$ \\
\hline Não migrante & $1995-2000$ & $-12,1$ & 12,3 & 19,8 & 7,7 \\
Outros migrantes & & $-13,2$ & 24,6 & 19,1 & $-9,4$ \\
RMSP & 9,5 & 0,2 & $-4,6$ & $-35,9$ \\
\hline Não migrante & $2005-2010$ & $-25,3$ & 3,9 & 14,6 & 31,2 \\
Outros migrantes & & $-12,0$ & 0,3 & 4,9 & 14,1 \\
RMSP & $-7,3$ & $-1,0$ & 6,5 & 0,8 \\
\hline
\end{tabular}

Fonte: IBGE. Censos Demográficos 1991, 2000 e 2010. Tabulações especiais dos autores.

\section{Das relações entre migração e segregação}

Uma vez que o processo de segregação socioespacial é influenciado e intensificado pela mobilidade espacial da população, um bom caminho para analisar esta relação seria verificar em quais zonas do município de Praia Grande estariam localizados os migrantes, levando-se em conta as condições socioeconômicas médias das mesmas. Assim, utilizando as informações das áreas de ponderação, esta seção busca fornecer indicações sobre como as diferentes modalidades migratórias podem impactar a diferenciação socioespacial existente na região.

De maneira geral, a análise dos dados sobre renda não deixa dúvidas de que a população em Praia Grande apresenta forte heterogeneidade em termos socioespaciais. De fato, como mostra o Mapa 1, são nítidas as distinções das zonas de concentração dos responsáveis pelo domicílio segundo o nível da renda. Embora entre 2000 e 2010 deva se reconhecer certa tendência de redução das diferenças relativas entre os mais ricos e os mais pobres (fato, em grande parte, devido às políticas de valorização do salário mínimo implementadas no período), observa-se claramente que existem zonas do território municipal reservadas àqueles com mais renda e outras destinadas àqueles com menos renda.

Mais especificamente, em virtude do caráter litorâneo do município, fica bem evidente uma seletividade na localização espacial dos grupos sociais segundo a renda, sendo que os mais abastados encontram-se, via de regra, muito mais intensamente nas zonas bem próximas à orla marítima. Esta é a "amenidade" natural principal do município e, portanto, um de seus principais condicionantes da produção do espaço regional e de suas localizações 
nos termos definido por Villaça (1998). ${ }^{11}$ Além disso, percebe-se que a Rodovia Padre Manoel da Nóbrega e a via de acesso a Praia Grande são as referências principais para a divisão social do espaço intraurbano.

MAPA 1

Renda média dos responsáveis pelo domicílio, segundo setores censitários e bairros selecionados Município de Praia Grande - 2000-2010

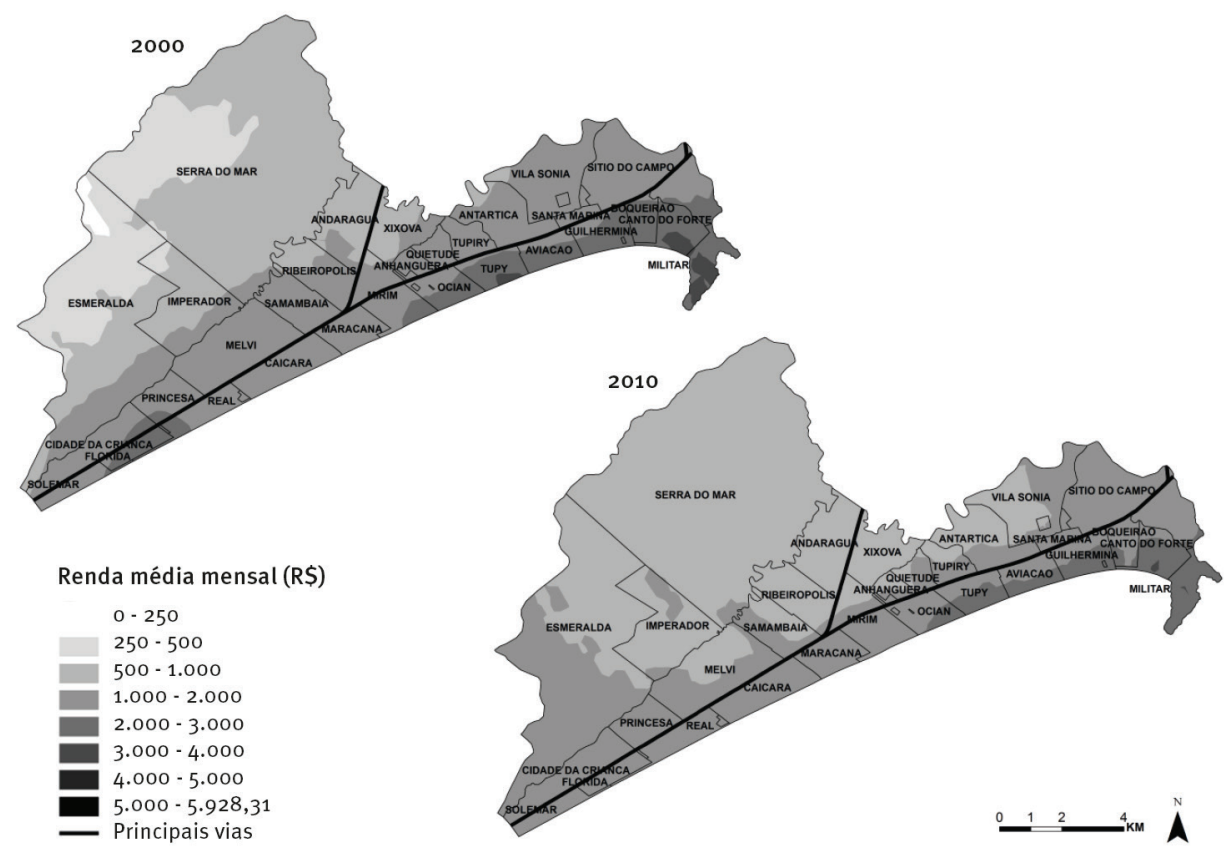

Fonte: IBGE. Censos Demográficos 2000 e 2010. Tabulações especiais dos autores.

Considerando que a imigração exerce um importante papel para o crescimento do município, assim como para sua peculiar inserção regional, supõe-se que a mesma também tenha posição relevante no tocante à dinâmica de estruturação do espaço intraurbano, segundo o processo descrito nos últimos parágrafos.

Assim, se é verdade que, em termos globais, não foram observadas grandes diferenças relativas ao perfil socioeconômico entre os dois tipos de migrantes que permitissem concluir a respeito dos impactos diferenciados das modalidades sobre o perfil do município, não resta qualquer dúvida que tal conclusão não pode ser reiterada quando se pensa no processo de estruturação do espaço intraurbano de Praia Grande.

\footnotetext{
${ }^{11}$ Segundo Villaça (1998, p. 74), as localizações urbanas consistem no "valor de uso produzido pelo trabalho coletivo dispendido na construção da cidade". A valorização de cada parte do espaço urbano está vinculada à maior ou menor acessibilidade aos efeitos úteis da aglomeração urbana que a sua localização pode propiciar.
} 
Tal constatação, considerada em conjunto com a análise dos dados sobre os rendimentos e níveis de instrução dos responsáveis pelos domicílios (Mapa 1 e Tabela 5), permite deduzir que a migração possui um papel importante para a segregação no município de Praia Grande, já que contribui para a manutenção da distância entre os mais ricos e os mais pobres.

De fato, de acordo com o Mapa 2 e a Tabela 5, enquanto um contingente relativamente alto de imigrantes intrametropolitanos tende a procurar as áreas mais distantes da orla (e mais baratas em termos do preço do solo), os imigrantes provenientes da RMSP, em volume relativamente maior, localizam-se, em sua maioria, nas áreas próximas à orla. Nessas últimas encontram-se as melhores localizações, em termos de amenidades e infraestrutura urbana, sendo, portanto, aquelas que apresentam os maiores preços do solo urbano.

Tais resultados reforçam o argumento de que, em Praia Grande, a migração tem impactos diferenciados não apenas no crescimento, mas também na composição socioeconômica do seu espaço intraurbano.

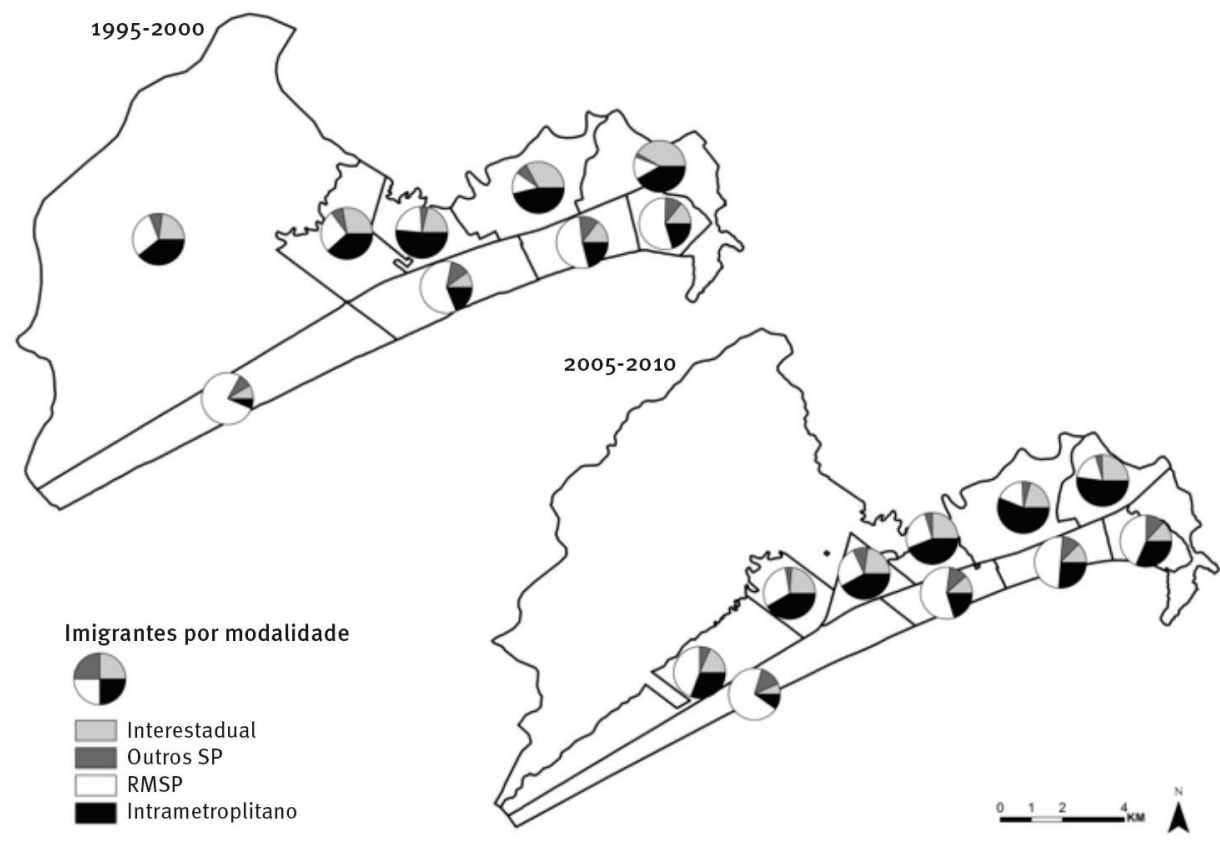

Fonte: IBGE. Censos Demográficos 2000 e 2010. Tabulações especiais dos autores.

Por fim, ao se relacionar o local de residência dos migrantes no espaço intraurbano com sua modalidade migratória e local de trabalho (Tabela 6), consegue-se melhor visualizar como as dinâmicas dos mercados de trabalho e de terras atuam enquanto condicionantes dos movimentos migratórios, especialmente daqueles de caráter metropolitano. 
TABELA 5

Migrantes de “data fixa” responsáveis por domicílios, por nível instrução, segundo local de residência e modalidade migratória

Município de Praia Grande - 2005/2010

\begin{tabular}{lcccccc}
\hline \multirow{2}{*}{ Residência } & $\begin{array}{c}\text { Modalidades } \\
\text { migratórias } \\
\text { principais }\end{array}$ & $\begin{array}{c}\text { Sem } \\
\text { instrução }\end{array}$ & $\begin{array}{c}\text { Fundamental } \\
\text { completo }\end{array}$ & $\begin{array}{c}\text { Médio } \\
\text { completo }\end{array}$ & $\begin{array}{c}\text { Superior } \\
\text { completo }\end{array}$ & $\begin{array}{c}\text { Total } \\
\text { (n. abs.) }\end{array}$ \\
\hline \multirow{2}{*}{ Orla } & RMBS & 15,8 & 14,6 & 40,1 & 29,4 & 2.048 \\
& RMSP & 26,4 & 22,5 & 32,7 & 18,3 & 6.355 \\
& Total & 31,4 & 18,9 & 32,0 & 17,7 & 37.935 \\
\hline Periferia & RMBS & 34,1 & 26,6 & 33,8 & 5,5 & 3.079 \\
& RMSP & 47,7 & 21,0 & 29,4 & 2,0 & 1.729 \\
& Total & 48,3 & 21,9 & 26,3 & 3,6 & 45.480 \\
\hline Praia Grande & RMBS & 26,8 & 21,8 & 36,3 & 15,1 & 5.127 \\
& RMSP & 31,0 & 22,2 & 32,0 & 14,8 & 8.084 \\
& Total & 40,6 & 20,5 & 28,9 & 10,0 & 83.415 \\
\hline
\end{tabular}

Fonte: IBGE. Censo Demográfico 2010. Tabulações especiais dos autores.

Verifica-se que, no agregado do município, em 2010, a maior parte dos migrantes (56,4\%) trabalhava nesta mesma cidade. De igual modo, entre os imigrantes intrametropolitanos e, principalmente, entre os provenientes da RMSP, os que trabalhavam em Praia Grande também detinham a maior participação relativa, com valores de 38,6\% e 62,6\%, respectivamente.

Entretanto, quando se desagregam os dados por áreas de ponderação, observa-se um comportamento bem mais heterogêneo quanto ao local de trabalho, com destaque para os grupos de migrantes que continuam trabalhando em seu município de residência cinco anos antes do recenseamento (residência prévia). Entre os imigrantes intrametropolitanos, ressalta-se o contingente relativamente maior de residentes nas áreas de ponderação mais afastadas da linha de costa (periféricas) cujo local de trabalho era o seu município de residência cinco anos antes (33,9\%). Este último resultado expressa a vigência de um processo de segregação residencial em escala regional, tendo em vista que muitos desses migrantes possivelmente migraram para as periferias de Praia Grande em razão de não poderem arcar com os altos custos do solo urbano próximo ao seu local de trabalho situado, de maneira geral, no núcleo metropolitano.

Já com relação aos imigrantes originários na RMSP, a situação mostra-se distinta, sendo que $23,3 \%$ daqueles que residiam na orla continuavam trabalhando no planalto, contra um percentual muito menor da mesma situação observada para os que foram viver nas áreas periféricas, apenas $7,4 \%$. Nesse caso, fica caracterizada uma seletividade social em relação a quem pode realizar o movimento pendular diário ao planalto, considerando, como já mencionado, o alto custo financeiro. Além disso, nestes casos fica patente, para parte significativa dos migrantes que chegam a Praia Grande, o efeito da dinâmica do mercado de terras que, mesmo num contexto aparentemente "inter-regional" (afinal envolveria duas RMs distintas), agiria como um importante condicionante dos movimentos migratórios do planalto para a baixada. 


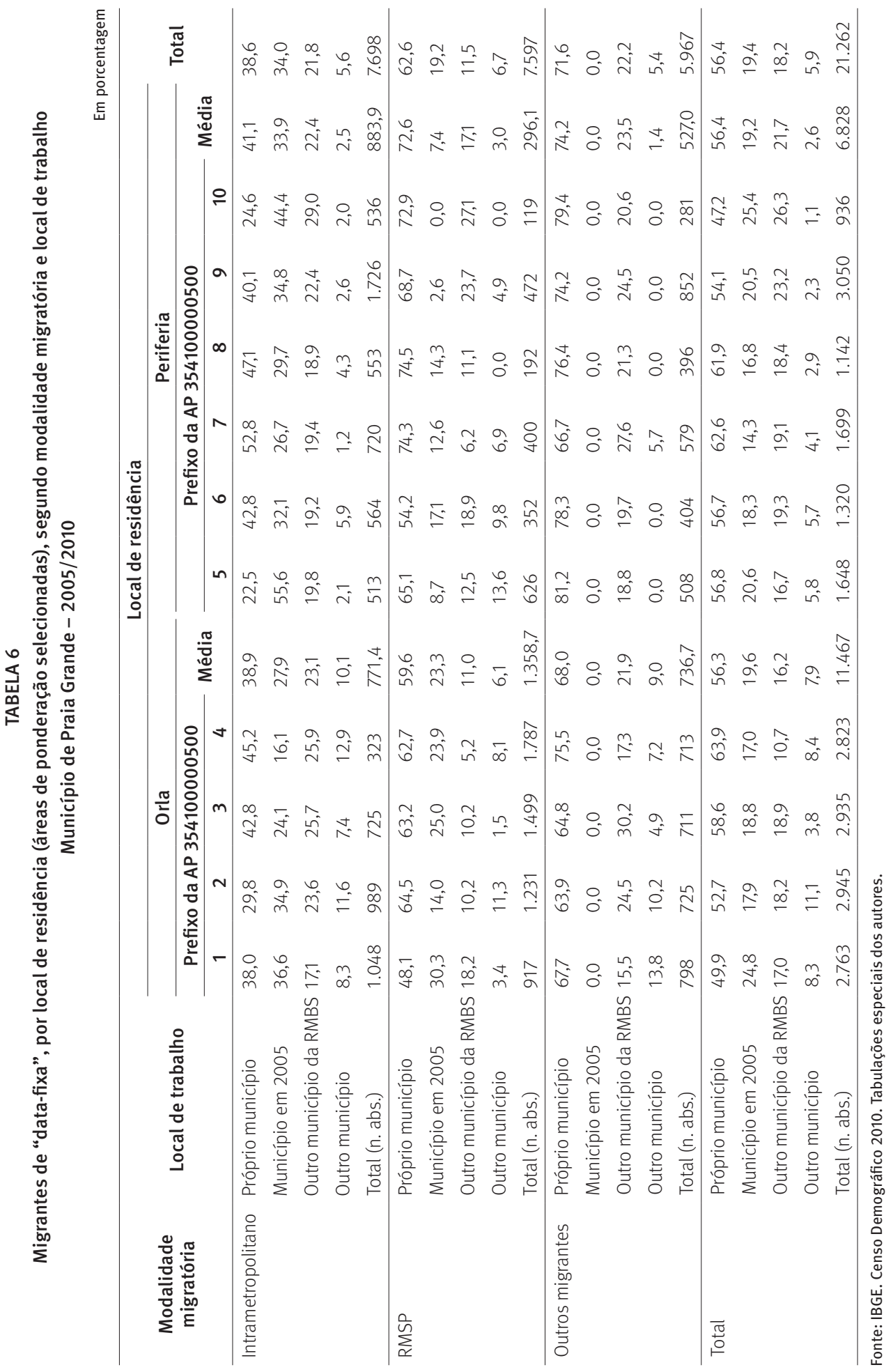




\section{Considerações finais}

Conforme mostrado ao longo do presente trabalho, o processo de expansão e estruturação urbana vivenciado pela Baixada Santista nos últimos anos esteve associado a contrapartidas sociodemográficas claras, as quais são importantes para o seu entendimento, considerando sua complexidade. Praia Grande foi talvez a municipalidade com mais destaque regional, já que apresentou o maior ritmo de crescimento populacional, igualmente mostrando-se como o destino preferencial de boa parte dos fluxos migratórios intrametropolitanos e inter-regionais que tiveram a RMBS como direção.

Examinando mais detalhadamente as nuances da migração, em especial a partir das características socioeconômicas dos migrantes, notou-se que existe uma diferença significativa conforme a origem destes. De forma geral, Praia Grande se conformou em um local que mantém ligação tanto com a própria RMBS (como, aliás, se observa em várias outras RMs), quanto com a RMSP, sendo que, neste caso, se caracteriza um exemplo de complementaridade que extrapola o nível regional. Nesse sentido, o vínculo de Praia Grande com tais regiões metropolitanas faz suscitar questões referentes ao seu peculiar papel enquanto um importante elo da articulação socioespacial desses espaços.

Dessa maneira, a mescla de dinâmicas socioespaciais nas escalas intraurbana e regional suscitou discussões sobre a real natureza dos processos envolvidos, uma vez que não se espera encontrar nestas duas escalas a mesma fluidez pelo território devido, principalmente, ao alto custo do translado envolvendo a última. Na verdade, as análises realizadas sugerem que o observado no caso de Praia Grande não guarda muitas semelhanças com o que seriam as dinâmicas socioespaciais próprias de uma perspectiva regional, sobretudo considerando o caráter de curta distância (que pode ser estruturado tanto pelos meios de comunicação quanto pelos meios de transporte) e a forte relação demográfica, medida a partir dos fluxos populacionais com o planalto paulista.

Assim, poder-se-ia perguntar: o movimento migratório originário do planalto poderia ser classificado como uma mobilidade residencial, nos termos propostos por Sobrino (2007), para designar os fluxos intrametropolitanos, ou se enquadraria no âmbito dos movimentos de mais longa distância?

Acredita-se que esta resposta não seja simples. No entanto, uma coisa é certa: o caráter peculiar de migração de curta distância, tanto a intrametropolitana quanto a originada na RMSP, teve importantes consequências socioespaciais para a dinâmica intraurbana do município. De fato, sua espacialização na escala intraurbana indicou o significativo peso de ambos os fluxos sobre a intensificação do processo de segregação residencial. Enquanto a migração proveniente da própria RMBS se destinou, predominantemente, para as áreas menos valorizadas dos municípios e, portanto, mais afastadas do litoral, a imigração originária da RMSP, por sua vez, colaborou com a parcela populacional em melhores condições socioeconômicas, direcionando-se majoritariamente às melhores localizações do município, próximas às praias e ao centro da cidade. 
Em suma, a partir das relações estabelecidas por Praia Grande com a própria RMBS e com a RMSP, suscita-se a retomada do debate levantado no começo deste trabalho acerca da validade e utilidade do conceito de centro-periferia e da dicotomia entre escala do espaço urbano e da rede urbana, tendo em vista a peculiar inserção regional do município.

Por um lado, o município assume o papel de uma "periferia tradicional" da RMBS, sendo o local da residência de significativa parcela da população, a qual, em virtude de seu menor poder aquisitivo, não pode arcar com altos custos do solo urbano do centro da região, capitaneado pela área insular de Santos. Por outro lado, Praia Grande assume, concomitantemente, muito mais o papel de uma periferia “elitizada" da cidade de São Paulo do que uma área privilegiada pelo processo de ocupação no estado de São Paulo. Isso porque os fluxos migratórios da RMSP para Praia Grande guardam muito mais características de movimentos intrametropolitanos do que de movimentos de longa distância, sendo condicionados, em grande parte, pela dinâmica do mercado de terras e trabalho, haja vista a grande quantidade de indivíduos que mantêm seus empregos no planalto.

Aceite-se ou não a ideia de que a dicotomia centro-periferia ainda pode ajudar significativamente na compreensão da formação e expansão do tecido urbano metropolitano, o fato é que, no caso de Praia Grande, os dados e as tendências sugeridas por eles atestam que o município não apenas apresenta uma forte segregação socioespacial, como também dá mostras de estabelecer uma complementaridade metropolitana com o planalto paulista, em especial com o município de São Paulo, transformando-se gradativamente em uma "nova periferia" ou frente de expansão urbana daquele município com uma grande vantagem, toda de frente para o mar.

Num exercício de prospecção e com base em observações de campo realizadas ao longo do processo de investigação da região, pode-se dizer que os resultados do Censo Demográfico de 2021 mostrarão com mais contundência a consolidação da "dupla função" de Praia Grande, tanto como uma periferia elitizada de São Paulo, quanto como alternativa para a população de mais baixa renda. No entanto, dada a tendência de redução do volume dos fluxos migratórios e o aumento da seletividade para os grupos sociais de poder aquisitivo mais elevado, espera-se que mesmo as áreas da periférica mais pobres do município tendam a apresentar maior heterogeneidade socioespacial.

Pode-se dizer que, embora esse estudo trate de um município em particular, não temos dúvidas de que as novas formas que vêm assumindo a urbanização, em geral, e a metropolização do espaço, em particular, fazem com que o caso de Praia Grande esteja longe de ser particular e único no espectro metropolitano brasileiro. Como mostra Silva (2018) em sua análise sobre a macrometrópole paulista, se o que vemos hoje em termos do processo de configuração das cidades-região parece ser expressão apenas do início de um processo mais complexo, certamente casos, como o aqui analisado, serão cada vez mais comuns, o que coloca novos e importantes desafios para os planejadores e formuladores de políticas. Se, no Brasil, o planejamento metropolitano ainda hoje carece de bases institucionais sólidas (sequer existem instâncias administrativas nessa base), o que dizer sobre o enfrentamento desse novo fenômeno do qual ainda pouco se conhece em termos de sua evolução e consequências? 


\section{Referências}

AZZONI, C. R. Indústria e reversão da polarização no Brasil. São Paulo: IPE-USP, 1986 (Ensaios Econômicos, n. 58).

BAENINGER, R. Migrações internas no Brasil século 21: evidências empíricas e desafios conceituais. In: CUNHA, J. P. (org.). Mobilidade espacial da população: desafios teóricos e metodológicos para o seu estudo. Campinas: Núcleo de Estudos de População - Nepo/Unicamp, 2011.

BONDUKI, N. J.; ROLNIK, R. Periferias: a ocupação do espaço e reprodução da força de trabalho. São Paulo: FAU/USP, 1979 (Cadernos de Estudos e Pesquisa, n. 2).

BÓGUS, L. M. Urbanização e metropolização: o caso de São Paulo. In: BÓGUS, L. M.; WANDERLEY, L. E. A luta pela cidade em São Paulo. São Paulo: Cortez, 1992.

BRITO, F. Brasil, final de século: a transição para um novo padrão migratório? In: ENCONTRO NACIONAL DE ESTUDOS POPULACIONAIS, 12, Caxambu, 2000. Anais [...]. Belo Horizonte: Abep, 2000.

BRITO, F. As migrações internas no Brasil: um ensaio sobre os desafios teóricos recentes. Belo Horizonte: Cedeplar/UFMG, 2009 (Texto para Discussão, n. 366).

CALDEIRA, T. Cidades de muros: crime, segregação e cidadania em São Paulo. São Paulo: Ed. 34-Edusp, 2000.

CASTRO, H. R.; SANTOS JUNIOR, W. R. A expansão da macrometrópole e a criação de novas RMs: um novo rumo para a metropolização institucional de São Paulo. Cadernos Metrópole, São Paulo, v. 19, n. 40, p. 703-720, set./dez. 2017.

FARIAS, L. A. C. Mobilidade populacional e produção do espaço urbano na Baixada Santista: um olhar sociodemográfico sobre sua trajetória nos últimos 20 anos. 2018, 213f. Tese (Doutorado em Demografia) - Instituto de Filosofia e Ciências Humanas, Universidade Estadual de Campinas (Unicamp), Campinas, 2018.

COSTA, H. (org.). Novas periferias metropolitanas. A expansão metropolitana em Belo Horizonte: dinâmica e especificidades no Eixo Sul. Belo Horizonte: C/Arte, 2006.

CUNHA, J. M. P. Mobilidade populacional e expansão urbana: o caso da Região Metropolitana de São Paulo. Campinas, SP: Librum Editora, 2015a. (Ebook)

CUNHA, J. M. P. A migração interna no Brasil nos últimos cinquenta anos: (des)continuidades e rupturas. In: ARRETCHE, M. Trajetórias das desigualdades: como o Brasil mudou nos últimos cinquenta anos. São Paulo: Editora Unesp; CEM, 2015b. p. 279-307.

CUNHA, J. M. P.; JAKOB, A. A. E (coord.). Atlas da Região Metropolitana da Baixada Santista. Campinas: Nepo/Unicamp, 2005.

DINIZ, C. C. Desenvolvimento poligonal no Brasil: nem desconcentração nem contínua polarização. Revista Nova Economia, Belo Horizonte, v. 31, n. 11, p. 35-64, set. 1993.

DOTA, E. M. Mobilidade residencial intrametropolitana na RM de Campinas: uma abordagem a partir da distribuição espacial dos migrantes. 2015. 221f. Tese (Doutorado em Demografia) Instituto de Filosofia e Ciências Humanas da Universidade Estadual de Campinas (Unicamp), Campinas, 2015.

DUPONT, V.; PUMAIN, D. De la ciudad compacta a las metrópolis policéntricas. In: DUREAU, F. et al. (coord.). Metrópolis en movimiento. Una comparación internacional. Bogotá, Colombia: Alfaomega, 2002.

FISHMAN, R. Burgeios utopias: visions of suburbia. In: FAINSTEIN, S.; CAMPBELL, S. (ed.) Readings in urban theory. Oxford: Blackwell Publishers, 1966. p. 23-60. 
JAKOB, A. A. E. Análise sociodemográfica da constituição do espaço urbano da Região Metropolitana da Baixada Santista no período 1960-2000. 2003. 220f. Tese (Doutorado em Demografia) - Instituto de Filosofia e Ciências Humanas, Universidade Estadual de Campinas (Unicamp), Campinas, 2003.

HARVEY, D. Condição pós-moderna. São Paulo: Loyola, 1992.

HARVEY, D. A justiça social e a cidade. São Paulo: Hucitec, 1980.

LEFEBVRE, H. O direito à cidade. São Paulo: Editora Documentos, 1968.

LENCIONI, S. Metropolização do espaço e a constituição de megarregiões. In: FERREIRA, A.; RUA, J.; MATTOS, R. C. de. (org.). Desafios da metropolização do espaço. 1. ed. Rio de Janeiro: Consequência, 2015. p. 35-68.

MARTINE, G. A redistribuição espacial da população brasileira durante a década de 80 . Rio de Janeiro: Ipea, 1994 (Texto para Discussão, 329).

MATOS, R. Questões teóricas acerca dos processos de concentração e desconcentração da população no espaço. Revista Brasileira de Estudos de População, Campinas, v. 12, n. 1-2, jan./dez. 1995.

MATTOS, C. A. Redes, nodos e cidades: transformação da metrópole latino-americana. In: RIBEIRO, L. C. Q. (org.). Metrópoles: entre a coesão e a fragmentação, a cooperação e o conflito. São Paulo: Perseu Abramo; Rio de Janeiro: Fase, 2004. p. 157-196.

MATTOS, C. A. Globalización y metamorfosis metropolitana en América Latina: de la ciudad a lo urbano generalizado. Revista de Geografía Norte Grande, Santiago de Chile, n. 10, p. 81-104, 2010.

MOURA, R. Arranjos urbano-regionais no Brasil: uma análise com foco em Curitiba. 2009. Tese (Doutorado em Geografia) - Universidade Federal do Paraná, Curitiba, 2009.

NAKANO, A. K. Elementos demográficos sobre densidade urbana: São Paulo, uma cidade oca? 2015. 348f. Tese (Doutorado em Demografia) - Instituto de Filosofia e Ciências Humanas, Universidade Estadual de Campinas (Unicamp), Campinas, 2015.

OLIVEIRA, H. S. Economia metropolitana e mercado de trabalho: um estudo das regiões metropolitanas do estado de São Paulo. 2009. Tese (Doutorado em Economia) - Universidade Estadual de Campinas (Unicamp), Campinas, 2009.

PINHO, B. A. T. D. População e pobreza: uma análise da Região Metropolitana de Belo Horizonte. 2016. 266f. Tese (Doutorado em Demografia) - Centro em Desenvolvimento e Planejamento Regional (Cedeplar), Universidade Federal de Minas Gerais (UFMG), Belo Horizonte, 2016.

REIS FILHO, N. G. Notas sobre urbanização dispersa e novas formas de tecido urbano. São Paulo: Via das Artes, 2006.

RIBEIRO, L. C. Q.; LAGO, L. Reestruturação nas grandes cidades brasileiras: o modelo centro/ periferia em questão. Rio de Janeiro: Instituto de Pesquisa e Planejamento Urbano e Regional da UFRJ, 1994.

RIGOTTI, J. I. R. Dados censitários e técnicas de análise das migrações no Brasil: avanços e lacunas. In: CUNHA, J. M. P. (org.). Mobilidade espacial da população: desafios teóricos e metodológicos para o seu estudo. Campinas: Nepo/Unicamp, 2011.

SANTOS, A. P. R. Praia Grande no contexto do processo de metropolização da Baixada Santista: mobilidade populacional e diversidade socioespacial. 2008. 166f. Dissertação (Mestrado em Demografia) - Instituto de Filosofia e Ciências Humanas da Universidade Estadual de Campinas (IFCH/Unicamp), Campinas, 2008. 
ROLNIK, R.; KOWARICK, L.; SOMEKH, N. São Paulo: crise e mudança. São Paulo: Brasiliense, 1990. SANTOS, M. Metrópole corporativa fragmentada: o caso de São Paulo. São Paulo: Nobel, 1990. SILVA, E. T. Estrutura urbana e mobilidade espacial nas metrópoles. Rio de Janeiro: Editora Letra Capital, 2013.

SILVA, K. A. A. Novas formas urbanas e o olhar através da demografia: a estruturação da CidadeRegião Paulista. 2018. Tese (Doutorado em Demografia) - Instituto de Filosofia e Ciências Humanas, Universidade Estadual de Campinas (IFCH/Unicamp), Campinas, 2018.

SINGH, J. P.; KUMAR, D. A technical note on index of migration differentials. Genus, Roma, v. 48, n. 1-2, p. 217-221, 1992.

SOBRINO, J. Patrones de dispersión intrametropolitana en México. Estudios Demográficos y Urbanos, v. 22, n. 3, p. 583-617, 2007.

SOUZA, M. A. Cidades médias e desenvolvimento industrial - uma proposta de descentralização metropolitana. São Paulo: Secretaria de Economia e Planejamento do Estado de São Paulo, 1978. (Série Estudos e Pesquisas, 17).

SPOSITO, M. E. B. Segregação socioespacial e centralidade urbana. In: VASCONCELOS, P. A.; CORRÊA, R. L.; PINTAUDI, S. M. (org.). A cidade contemporânea: segregação espacial. São Paulo: Contexto, 2013. p. 61-93.

TASCHNER, S. P.; BOGUS, L. M. M. A cidade dos anéis: São Paulo. In: RIBEIRO, L. C. Q. (org.). O futuro das metrópoles: desigualdades e governabilidade. Rio de Janeiro: Revan, 2000.

VILLAÇA, F. Espaço intraurbano no Brasil. São Paulo: Studio Nobel; Fapesp; Lincoln Institute, 1998.

\title{
Sobre os autores
}

José Marcos Pinto da Cunha é demógrafo, doutor em Ciências Sociais pela Universidade Estadual de Campinas (Unicamp). Professor titular do Instituto de Filosofia e Ciências Humanas e pesquisador do Núcleo de Estudos de População "Elza Berquó" (Nepo), ambos da Unicamp.

Luiz Antonio Chaves de Farias é demógrafo, doutor em Demografia pela Universidade Estadual de Campinas (Unicamp) e mestre em Geografia pela Universidade Federal do Rio de Janeiro (UFRJ).

Alberto Augusto Eichman Jakob é demógrafo, doutor em Demografia pela Universidade Estadual de Campinas (Unicamp). Pesquisador do Núcleo de Estudos de População "Elza Berquó" (Nepo) e professor do Programa de Pós-Graduação em Demografia do Instituto de Filosofia e Ciências Humanas, ambos da Unicamp.

\section{Endereço para correspondência}

\author{
José Marcos Pinto da Cunha \\ Rua Dois, n. 291, Residencial Paineiras, Betel \\ 13148-251 - Paulínia-SP, Brasil \\ Luiz Antonio Chaves de Farias \\ Rua Manoel de Araújo, n. 464 apto. 102, Irajá \\ 21230-370 - Rio de Janeiro-RJ, Brasil
}




\author{
Alberto Augusto Eichman Jakob \\ Rua Armando Semartelli, n. 15 \\ 13148-254 - Paulínia-SP, Brasil
}

\begin{abstract}
One periphery, two centers: the municipality of Praia Grande in the context of the formation of the macrometropolis of São Paulo at the beginning of the 21st century
\end{abstract}

The present study has two main objectives: the first one is to discuss the impacts, consequences and demographic responses of the process of expansion and structuring of large urban agglomerations, with special focus on the case of Praia Grande/SP in the Metropolitan Area of Baixada Santista; the second one, to examine in more detail the nuances of population mobility and, in particular, migratory modalities (and their characteristics), as important elements of the peculiar regional insertion of that municipality as "simultaneous periphery" of two metropolitan areas. Based on the exhaustive use of census data, especially the Demographic Census of 2000 and 2010, this study presents an analysis of the growth and territorial expansion of Praia Grande emphasizing, at intra-municipal level, the role of the different migration modalities (intra-metropolitan and inter-regional). In addition, it seeks to associate them to different motivations from a detailed look at the sociodemographic profile of established flows. As main results of the work, it was observed that the role of Praia Grande as an area of metropolitan expansion of RMBS is supported by the growing intra-metropolitan migratory flows from the regional core, a reality that can also be observed in other metropolitan contexts. However, as a peculiarity of its process of occupation and regional insertion, a major part of this migration comes from outside the RMBS, more precisely, from the municipality of São Paulo, the center of another important metropolitan area, a fact that contributes to characterize Praia Grande as a "periphery with two centers".

Keywords: Metropolization. Urban expansion. Population mobility. Residential mobility. Socioespatial dynamic. Pherifery. Intrametropolitan migration. Internal migration.

\title{
Resumen
}

Una periferia, dos centros: el municipio de Praia Grande en el contexto de la formación de la macrometrópolis de São Paulo a principios del siglo XXI

El presente estúdio tiene dos objetivos principales: el primero, discutir los impactos, las consecuencias y las respuestas demográficas del proceso de expansión y estructuración de grandes aglomeraciones urbanas, con énfasis en el caso de Praia Grande (São Paulo) en la Región Metropolitana de Baixada Santista (RMBS); el segundo, examinar con más detalle los matices de la movilidad de la población y, en particular, de las modalidades migratorias (y sus características), como elementos importantes de la peculiar inserción regional del município como una "periferia simultánea" de dos regiones metropolitanas. A partir de los datos del censo, especialmente de los censos de 2000 y 2010, el estúdio presenta un análisis del crecimiento y la expansión territorial de Praia Grande con énfasis en el proceso intramunicipal, el papel de las diferentes modalidades de migración (intrametropolitana e interregional). Además, busca asociar estos movimientos a diferentes motivaciones a partir de una mirada sobre el perfil 
sociodemográfico de los flujos establecidos. Como resultado principal del trabajo, se observó que el papel de Praia Grande como área de expansión metropolitana de la RMBS es respaldado por el incremento de los flujos migratórios intrametropolitanos con origen en el polo regional, una realidad que también se puede ver en otros contextos metropolitanos. Sin embargo, como peculiaridad de su proceso de ocupación e inserción regional, parte significativa de esa migración se origina fuera de la RMBS, más precisamente, en la ciudad de São Paulo, cientro de otra región metropolitana (la Región Metropolitana de São Paulo), hecho que contribuye a caracterizar el municipio de Praia Grande como una "periferia de dos centros".

Palabras clave: Metropolización. Expansión urbana. Movilidad de la población. Movilidad residencial. Dinámica socioespacial. Periferia. Migración intrametropolitana. Migración interna.

Recebido para publicação em 13/11/2019

Aceito para publicação em 13/01/2020 